\title{
A longitudinal study of dehydroepiandrosterone sulphate (DHEAS) change in older men and women: the Rancho Bernardo Study
}

\author{
Cara Tannenbaum, Elizabeth Barrett-Connor ${ }^{1}$, Gail A Laughlin ${ }^{1}$ and Robert W Platt ${ }^{2}$ \\ Centre de Recherche de l'Institut Universitaire de Gériatrie de Montréal, Department of Medicine, Université de Montréal, 4565 Queen Mary Road, \\ Suite 7824, Montreal, Quebec, Canada H3W 1W5, ${ }^{1}$ Department of Family and Preventive Medicine, School of Medicine, University of California, \\ San Diego 0607, La Jolla, California 92093-0607, USA and ${ }^{2}$ Department of Epidemiology and Biostatistics and Department of Pediatrics, 4060 Saint \\ Catherine Street West, McGill University, Montreal, Quebec, Canada H3Z 2 Z3 \\ (Correspondence should be addressed to E Barrett-Connor; Email: ebarrettconnor@ucsd.edu)
}

\begin{abstract}
Objective: To examine the age-related and sex-specific rates and determinants of change in endogenous dehydroepiandrosterone sulphate (DHEAS) levels in older community-dwelling adults, taking into account regression to the mean.

Design: Prospective cohort study from Rancho Bernardo, California, USA.

Methods: Plasma for DHEAS was collected at baseline and 10-14 years later from 242 men and 207 postmenopausal women (age range, 60-77 years), who were not taking hormone therapy or corticosteroids. Age-related and sex-specific changes in DHEAS were calculated according to four different definitions of change: absolute change, annual percentage change, change exceeding $10 \%$ of baseline and change exceeding that expected from statistical regression to the mean. Determinants of DHEAS change were assessed using regression analyses.

Results: Baseline DHEAS levels were higher for men than women (age-adjusted means, $1.37 \pm 0.73 \mu \mathrm{g} / \mathrm{ml} \quad(3.72 \pm 1.98 \mu \mathrm{mol} / \mathrm{l}) \quad$ vs $0.73 \pm 0.48 \mu \mathrm{g} / \mathrm{ml} \quad(1.98 \pm 1.30 \mu \mathrm{mol} / \mathrm{l})$ respectively, $P<0.0001)$, with more pronounced declines observed in men $(-4.0 \% /$ year $)$ compared with women $(-2.1 \% /$ year; $P<0.001)$. Some $28 \%$ of women and $5 \%$ of men had DHEAS levels that increased or stayed the same according to a 10\% definition of change. When regression to the mean artifact was accounted for, only $15 \%$ of women and $5 \%$ of men showed true increases in DHEAS. In both sexes, baseline DHEAS levels accounted for three-quarters of the variability in absolute DHEAS change over time, with higher baseline levels resulting in greater loss. Sex, baseline weight, age and smoking status were significantly associated with DHEAS change in univariate models; only sex remained independently associated with DHEAS change in multivariate analyses, with men showing greater annual declines than women (estimated coefficient $=0.006, P=0.008$ ). Conclusion: In this sample, over 30\% of the observed changes in DHEAS could be attributed to regression to the mean. Potential underlying mechanisms of change in DHEAS levels, and sex differences, are discussed.
\end{abstract}

European Journal of Endocrinology 151 717-725

\section{Introduction}

Dehydroepiandrosterone (DHEA) and its sulphate form (DHEAS) are the most abundant endogenous sex hormones in ageing men and women $(1,2)$. DHEAS is produced in the adrenal cortex and is converted to androgens and oestrogens in peripheral tissues $(2,3)$. It provides close to $100 \%$ of active oestrogens in postmenopausal women, and up to $50 \%$ of androgens in older men and women $(2,4,5)$.

Cross-sectional studies have shown significant agerelated declines in circulating levels of DHEAS among older men and women $(4,6)$; however, longitudinal studies suggest that DHEAS levels may actually increase in $10-40 \%$ of older adults (7-9). This discrepancy remains largely unexplained. It could be due to the way that change is defined in each of the studies or to the influence of a regression to the mean phenomenon $(8,9)$. Regression to the mean describes the tendency of high or low values of a biological marker to return towards the mean upon re-testing (10-13). Biological variability within the individual and measurement error are thought to underlie this statistical phenomenon. Regression to the mean has been studied in relation to blood pressure changes over time (14), but the concept applies equally to changes in serum hormone levels. The importance of regression towards the mean is that it can result in overestimation 
or underestimation of true change, and lead to erroneous conclusions about the natural progression of biological markers such as DHEAS over time. The effect of regression toward the mean in studies of DHEAS change has never formally been tested.

The physiological significance of DHEAS change and the factors that determine DHEAS levels also remain unclear. Converging evidence suggests that low DHEAS levels may have important but different roles in men and women with regard to cardiovascular mortality (15-22), cognitive decline $(15,23-29)$, accelerated bone loss $(30-32)$, depression $(23,33)$ and cancer (34-37). A better understanding of the factors that influence the magnitude and direction of DHEAS change in ageing men and women is required to characterize the natural progression and clinical significance of this hormone. The present study aims to clarify the age-related and sex-specific rates and determinants of change in DHEAS levels in communitydwelling older adults, taking into account a possible regression to the mean phenomenon.

\section{Subjects and methods}

\section{Subjects}

Subjects are 449 men and women aged 60 years and older with baseline and 10- to 14-year follow-up DHEAS measurements who were enrolled in a population-based longitudinal cohort study of heart disease risk factors in the geographically defined community of Rancho Bernardo, California, USA. All women were postmenopausal. Subjects were excluded if they were taking oestrogens, progestins or corticosteroids at baseline $(1972-1974)$ or follow-up (1984-1987).

\section{DHEAS measurements}

Venous blood for DHEAS assay was obtained from each subject at baseline and at a 10- to 14-year follow-up visit. Blood samples were obtained between 0730 and $1100 \mathrm{~h}$, after a requested 12-h fast, and the plasma was separated and frozen at $-70^{\circ} \mathrm{C}$. Between 1985 and 1986, the baseline plasma specimens were first thawed and DHEAS was measured by direct RIA in an endocrinology research laboratory at the University of California, San Diego; 10-14 years later (19841987), blood from a second visit was obtained and frozen for future analysis. Between 1992 and 1994, first-thawed plasma from the second visit was assayed for DHEAS in the same laboratory, by the same technician, using the same RIA technique. The sensitivity and intra-assay and inter-assay coefficients of variation for the DHEAS assays were $0.15 \mu \mathrm{g} / \mathrm{ml}(0.41 \mu \mathrm{mol} / \mathrm{l})$ and $4.2 \%$ and $8.8 \%$ respectively.

\section{Health parameters}

A standardized health questionnaire including questions about basic demographics and current cigarette smoking (yes/no) was completed by the participants at each visit. Height $(\mathrm{m})$ and weight (kg) were measured with the participants wearing lightweight clothing without shoes. Body mass index (BMI) (weight $(\mathrm{kg}) /$ height $\left(\mathrm{m}^{2}\right)$ ) was used as an estimate of obesity. Weight change and BMI change were calculated as weight and BMI measured at the 19841987 visit subtracted from weight and BMI measured at the 1972-1974 visit respectively. Vital status was determined for $99.9 \%$ of the cohort during a 15-year follow-up. Each participant gave written informed consent to participate at each clinic visit.

\section{Defining change in DHEAS}

Absolute changes in intra-individual DHEAS levels across the 10- to 14-year study period were calculated by subtracting the DHEAS level measured at the initial visit from the DHEAS level measured at the follow-up visit. The percentage change - or relative change in DHEAS was calculated as an individual's absolute change in DHEAS divided by their baseline DHEAS level. We studied the distribution of change beyond what might be accounted for by measurement error and biological variability according to two separate definitions of 'real' change. The first was an intra-individual increase or decrease in DHEAS of greater than $10 \%$ from baseline over the follow-up period. This $10 \%$ value was based on the inter-assay coefficient of variation and other estimates of DHEAS stability and intra-individual reproducibility over time in older adults $(38,39)$. A second calculation of change due to measurement error and biological variability was carried out by simulating DHEAS follow-up values based entirely on statistical regression to the mean criteria. For each participant, we simulated the expected change in DHEAS due to regression to the mean, subtracted the observed baseline measure from this value, and then compared the expected change in DHEAS due to regression to the mean with the absolute change in DHEAS observed during the study period. To simulate regression to the mean follow-up values of DHEAS, we used the formula according to Streiner (11):

$$
T_{2}=\bar{X}+r\left(T_{1}-\bar{X}\right)
$$

where: $T_{1}$ is the person's initial DHEAS level at baseline; $\mathrm{T}_{2}$ is the simulated follow-up score; $\bar{X}$ is the sex-specific mean for the observed baseline and follow-up DHEAS values; $r$ is the sex-specific correlation between the observed baseline and follow-up measures. Participants were classified as having a decrease in DHEAS if their absolute change in DHEAS was less than (e.g. was algebraically more negative than) the expected change due to 
regression to the mean; non-decliners were those who showed increases in DHEAS as defined by an absolute change in DHEAS that exceeded (e.g. was algebraically more positive than) the expected change due to regression to the mean.

Fifteen participants at baseline and 36 at follow-up had DHEAS levels that were below the assay sensitivity. These participants were assigned the minimum threshold value of $0.15 \mu \mathrm{g} / \mathrm{ml}(0.41 \mu \mathrm{mol} / \mathrm{l})$. Nine participants had DHEAS levels below the assay sensitivity at both baseline and follow-up. According to the $10 \%$ cut-off distribution of change criteria, these subjects were classified as having stayed the same.

\section{Statistical analysis}

Statistical analyses were conducted using the SAS software package (version 8.2, SAS Institute, Cary, NC, USA). Subject characteristics were summarized according to basic descriptive statistics for means and proportions. To ascertain response bias, Student's $t$-tests and $\chi^{2}$ analyses were used to compare baseline characteristics across sex and age strata for participants who came to both visits versus those who had died prior to the second clinical visit or who had survived to the second visit but who did not have repeat DHEAS measurements. Age-adjusted mean baseline DHEAS levels for the different groups were computed using analysis of covariance PROC GLM.

Correlations between baseline and follow-up DHEAS levels as well as with DHEAS change were computed using PROC CORR. The sex- and age-adjusted partial correlation of baseline and follow-up DHEAS measures was calculated using the PARTIAL option to determine the strength of this relationship when the effects of sex and age were removed. Changes in DHEAS according to different definitions of change were calculated using basic descriptive statistics. The percentage change in DHEAS that could be accounted for by regression to the mean was calculated as $100(1-$ partial $r)$ where partial $r$ is the sex- and age-adjusted partial correlation of baseline and follow-up DHEAS measures in this sample (12).

Determinants of annual absolute change in DHEAS in the study group were evaluated using linear regression and determinants of categorical change were evaluated using logistic regression. Participants whose DHEAS levels declined by greater than $10 \%$ were compared with those whose levels stayed the same or increased by $10 \%$. In a separate analysis, participants whose change in DHEAS exceeded what was expected due to regression to the mean were compared with those whose DHEAS change was less than what was expected due to regression to the mean. Baseline DHEAS levels, age, sex, BMI, baseline body weight, weight change, change in BMI and baseline smoking status were evaluated as potential predictors of DHEAS change. Predictors were first tested individually, using univariate regression. Predictors that emerged as significant in univariate testing $(P<0.1)$ were then introduced into multivariate models. Logistic regression analyses were used to differentiate women whose DHEAS levels increased or stayed the same from those whose DHEAS levels decreased (this was not possible for men because few had DHEAS levels that increased or stayed the same). To test whether increases in DHEAS were associated with lower initial DHEAS levels, a DHEAS cut-off value corresponding to the lowest quartile of baseline DHEAS in women $(0.38 \mu \mathrm{g} / \mathrm{ml}(1.03 \mu \mathrm{mol} / \mathrm{l}))$ was selected as a predictor. Results are presented as regression coefficients (beta estimates) and proportion of explained variance $\left(R^{2}\right)$ of the linear models, and as odds ratios with $95 \%$ confidence intervals (OR $\pm 95 \% \mathrm{CI}$ ) for logistic models.

\section{Results}

\section{Demographic characteristics}

Among 1279 potentially eligible subjects who had DHEAS measurements at baseline, 444 died prior to the 12-year follow-up; among those who survived, 386 did not return for repeat DHEAS testing. The remaining 449 subjects are the focus of this report. Of these, 242 were men (mean age, 67.1 \pm 3.7 years; range, 60-77 years) and 207 were women (mean age, 66.7 \pm 4.1 years; range, 60-76 years). The characteristics of the 449 study participants compared with the group of 444 subjects who died, and the 386 subjects who survived but did not have repeat DHEAS measurements, are presented in Table 1. As shown, those who died were older and more likely to smoke than the study participants. Although baseline DHEAS levels were significantly lower in men (but not women) who died prior to the follow-up visit, this difference was not significant after adjusting for age using analysis of covariance.

\section{DHEAS change over time}

Age-related and sex-specific rates of absolute, relative and 'real' changes in DHEAS over the 10- to 14-year follow-up (mean 11.8 \pm 0.8 years) are presented in Tables 2 and 3. At baseline and at follow-up DHEAS levels were higher for men than women in every age group $(P<0.0001)$. Annual rates of decline were consistently more pronounced in men than in women (age-adjusted means, $-4.0 \%$ vs $-2.1 \%$ respectively; $P<0.0001)$. Relative rates of change remained stable for men and women across age groups. Overall, only $5 \%$ of men showed a stable or increasing level of DHEAS over time according to both the $\pm 10 \%$ criteria for change as well as the regression to the mean criteria. In contrast, DHEAS levels were stable or increased in $28 \%$ of women according to the $\pm 10 \%$ 
Table 1 Baseline characteristics of subjects included and excluded from the study.

\begin{tabular}{|c|c|c|c|c|c|c|}
\hline & \multicolumn{2}{|c|}{$\begin{array}{l}\text { Study population } \\
\qquad(n=449)\end{array}$} & \multicolumn{2}{|c|}{$\begin{array}{l}\text { Alive but no DHEAS } \\
\text { follow-up }(n=386)\end{array}$} & \multicolumn{2}{|c|}{$\begin{array}{l}\text { Died prior to 12-year } \\
\text { follow-up (all cause } \\
\text { mortality; } n=444)\end{array}$} \\
\hline & $\begin{array}{c}\text { Men } \\
(n=242)\end{array}$ & $\begin{array}{l}\text { Women } \\
(n=207)\end{array}$ & $\begin{array}{c}\text { Men } \\
(n=185)\end{array}$ & $\begin{array}{l}\text { Women } \\
(n=201)\end{array}$ & $\begin{array}{c}\text { Men } \\
(n=280)\end{array}$ & $\begin{array}{l}\text { Women } \\
(n=164)\end{array}$ \\
\hline $\begin{array}{l}\text { Mean age } \pm \text { S.D. } \\
\text { Age range (vears) }\end{array}$ & $\begin{array}{c}67.1 \pm 3.7 \\
60-77\end{array}$ & $\begin{array}{c}66.7 \pm 4.1 \\
60-76\end{array}$ & $\begin{array}{l}68.1 \pm 5.0^{*} \\
60-79\end{array}$ & $\begin{array}{l}68.4 \pm 5.2^{*} \\
60-82\end{array}$ & $\begin{array}{l}70.3 \pm 5.0^{\star} \\
60-82\end{array}$ & $\begin{array}{l}71.5 \pm 5.7^{*} \\
60-88\end{array}$ \\
\hline $\begin{array}{l}\text { Age range (years) } \\
\text { Weight } \pm \text { S.D. (kg) }\end{array}$ & $77.4 \pm 10.4$ & $63.7 \pm 10.3$ & $77.5 \pm 10.0$ & $61.8 \pm 10.0$ & $76.0 \pm 10.2$ & $\begin{array}{l}60-88 \\
62.0 \pm 10.7\end{array}$ \\
\hline$B M I \pm S . D$. & $25.6 \pm 2.9$ & $24.8 \pm 3.8$ & $25.8 \pm 2.8$ & $24.5 \pm 3.9$ & $25.4 \pm 2.9$ & $24.7 \pm 4.2$ \\
\hline Current smoker (\%) & 12.4 & 13.0 & 15.7 & $24.4^{*}$ & 17.5 & $22.0^{*}$ \\
\hline $\begin{array}{l}\text { Mean baseline DHEAS }(\mu \mathrm{g} / \mathrm{ml}) \\
(\mu \mathrm{mol} / \mathrm{l})\end{array}$ & $\begin{array}{c}1.36 \\
(3.69)\end{array}$ & $\begin{array}{c}0.74 \\
(2.00)\end{array}$ & $\begin{array}{l}1.31 \\
(3.55)\end{array}$ & $\begin{array}{c}0.76 \\
(2.06)\end{array}$ & $\begin{array}{l}1.18^{*} \\
(3.20)\end{array}$ & $\begin{array}{c}0.71 \\
(1.93)\end{array}$ \\
\hline $\begin{array}{l}\text { Mean age-adjusted baseline DHEAS } \\
(\mu \mathrm{g} / \mathrm{ml})(\mu \mathrm{mol} / \mathrm{l})\end{array}$ & $\begin{array}{c}1.29 \\
(3.50)\end{array}$ & $\begin{array}{c}0.71 \\
(1.93)\end{array}$ & $\begin{array}{l}1.29 \\
(3.50)\end{array}$ & $\begin{array}{c}0.76 \\
(2.06)\end{array}$ & $\begin{array}{l}1.26 \\
(3.42)\end{array}$ & $\begin{array}{l}0.75 \\
(2.04)\end{array}$ \\
\hline $\begin{array}{l}\text { DHEAS range }(\mu \mathrm{g} / \mathrm{ml}) \\
(\mu \mathrm{mol} / \mathrm{l})\end{array}$ & $\begin{array}{l}0.20-4.93 \\
(0.54-13.38)\end{array}$ & $\begin{array}{l}0.15-3.00 \\
(0.41-8.14)\end{array}$ & $\begin{array}{l}0.24-3.80 \\
(0.65-10.31)\end{array}$ & $\begin{array}{c}0.15-3.51 \\
(0.41-9.53)\end{array}$ & $\begin{array}{l}0.15-4.95 \\
(0.41-13.43)\end{array}$ & $\begin{array}{c}0.15-3.32 \\
(0.41-9.01)\end{array}$ \\
\hline
\end{tabular}

${ }^{*} P<0.05$ compared to study population.

criteria, and in $15 \%$ according to the regression to the mean criteria.

Accordingly, only $10 \%$ of the total sample $(5 \%$ of men and $15 \%$ of women) showed 'real' increases in DHEAS when regression to the mean was accounted for.

\section{Correlations between baseline and follow-up DHEAS levels and DHEAS change}

Baseline DHEAS levels were highly correlated with follow-up DHEAS levels $(r=0.69$ for men and 0.73 for women; $P<0.0001$ for both) and with DHEAS change $(r=-0.87$ for men and -0.72 for women; $P<0.0001$ for both). The sex- and age-adjusted partial correlation between baseline and follow-up DHEAS levels was 0.69. The percentage change in DHEAS that could be accounted for by regression to the mean was calculated to be $31 \%$. Analyses were repeated excluding subjects whose DHEAS levels at baseline or follow-up fell below the assay sensitivity, with no measurable changes in the results.

\section{Determinants of DHEAS change}

Age, sex, baseline DHEAS, baseline weight and smoking status were significantly associated with annualized change in DHEAS in univariate analyses (Table 4). Only baseline DHEAS and sex remained independently associated with DHEAS change in multivariate models. The relationship between baseline weight and DHEAS change was confounded by sex, and the effects of age and smoking status on DHEAS change no longer remained significant when adjusted for baseline DHEAS levels. Baseline DHEAS was clearly the most important predictor, accounting for $74 \%$ of the variability in DHEAS change. Figure 1 illustrates the association of higher baseline values of DHEAS with larger negative change, and lower baseline values with smaller declines or even increases in DHEAS.

Logistic regression analyses were used to differentiate those women whose DHEAS levels increased or stayed the same from those whose DHEAS levels decreased. Using the $\pm 10 \%$ criteria for change, having DHEAS levels in the lowest quartile of baseline DHEAS was the only significant predictor of an increase in DHEAS levels (for baseline DHEAS levels less than or equal to $0.38 \mu \mathrm{g} / \mathrm{ml}$, OR 2.41 , 95\% CI 1.21-4.81). Smoking status - and increases in body weight, BMI and age - were not associated with the direction of DHEAS change. In analyses looking only at women in whom DHEAS increases exceeded those attributable to regression to the mean, low baseline DHEAS levels did not remain a statistically significant predictor of 'real' change.

Determinants of the direction of DHEAS change in older men were not possible in this study as there were insufficient numbers of men in whom DHEAS levels did not decrease.

\section{Discussion}

Data from this longitudinal study show that plasma DHEAS levels continued to decline in most participants after age 60 , but with marked individual variability in both sexes. Declines in DHEAS were more pronounced and nearly universal in men while women were more likely to show smaller declines or have an increase in DHEAS levels. Baseline DHEAS was the most important predictor of DHEAS change, with sex being the only other independent predictor. Smoking status, age and baseline weight possibly exerted small additional effects on DHEAS change through their effects on baseline DHEAS.

These findings confirm the overall age-related trend of lower circulating DHEAS levels observed in 
Mean values are shown \pm S.D.

Table 3 DHEAS change over a 12-year time period in women.

Range of 10- to

Age Mean baseline $\quad$ Range of Mean 10- to 14-year

DHEAS $(\mu \mathrm{g} / \mathrm{ml})$ bas

$(\mu \mathrm{mol} / \mathrm{l}) \quad(\mu \mathrm{g} / \mathrm{ml})(\mu \mathrm{mol} / \mathrm{l}) \quad(\mu \mathrm{g} / \mathrm{ml})(\mu \mathrm{mo} / /)$

$(4.03 \pm 1.75)$

65-69 $121 \quad 1.36 \pm 0.69$

\begin{tabular}{rrr}
$70-74 \quad 52 \quad 1.29 \pm 0.92$ \\
\hline
\end{tabular}

$75+\quad 8 \quad(3.50 \pm 2.52)$

$75+(8-0.87 \pm 0.26$

All $\quad 242 \quad 1.36 \pm 0.74$

$(3.69 \pm 2.00)$

$0.45-3.32$

$(1.22-9.01)$

$0.20-4.35$

$(0.54-11.81)$

$0.24-4.93$
$(0.65-13.39)$

$0.54-1.34$

$(1.47-3.64)$

$(0.54-13.38)$

$0.69 \pm 0.37$

$(1.89 \pm 1.00)$

$0.67 \pm 0.38$
$(1.82 \pm 1.05)$

$(1.82 \pm 1.05)$
$0.61 \pm 0.38$

$(1.68 \pm 1.03)$

$(1.68 \pm 1.03)$

$(1.28 \pm 0.79)$

$0.67 \pm 0.38$

$(1.82 \pm 1.03)$
DHEAS $(\mu \mathrm{g} / \mathrm{ml}) \pm \mu \mathrm{mol} / \mathrm{l})$

$0.15-1.57$

$(0.41-4.26)$

$(0.41-5.32)$

$(0.41-5.32)$

$(0.41-4.64)$

(0.41-4.64)

$0.15-0.87$

$0.15-1.96$

$(0.41-5.32)$

Distribution of

change by

Distribution of change regression to the by $\pm 10 \% \quad$ mean criteria

10- to 14-year

Annual differentage

Decrease Same Increase Decrease Increase

\begin{tabular}{llllll} 
change & $\begin{array}{c}\text { Decre } \\
\text { DHEAS }\end{array}$ & $(\%)$ & $(\%)$ & $(\%)$ & $(\%)$ \\
\hline
\end{tabular}

$-0.78 \pm 0.50$

$-4.3 \pm 2.0$

$(-2.13 \pm 1.37)$

$-0.66 \pm 0.49$
$(-1.81+1.35)$

$(-1.81 \pm 1.35)$

$(-1.83 \pm 1.92)$

$(-1.83 \pm 1.92)$
$-0.39 \pm 0.23$

$(-1.08 \pm 0.63)$

$-0.69 \pm 0.55$
$(-1.87 \pm 1.49)$

$-4.1 \pm 1.9$

95
97

$-3.7 \pm 3.2$

$-3.8 \pm 2.0$

$-4.0 \pm 2.2$

97

92

88

21

96

4

\begin{tabular}{|c|c|c|c|c|c|c|c|c|c|c|c|c|}
\hline \multirow{2}{*}{$\begin{array}{l}\text { Age } \\
\text { group } \\
\text { (years) }\end{array}$} & \multirow[b]{2}{*}{$n$} & \multirow{2}{*}{$\begin{array}{c}\text { Mean baseline } \\
\text { DHEAS }(\mu \mathrm{g} / \mathrm{ml}) \\
\quad(\mu \mathrm{mol} / \mathrm{l})\end{array}$} & \multirow{2}{*}{$\begin{array}{c}\text { Range of } \\
\text { baseline DHEAS } \\
(\mu \mathrm{g} / \mathrm{ml})(\mu \mathrm{mol} / \mathrm{l})\end{array}$} & \multirow{2}{*}{$\begin{array}{l}\text { Mean 10- to 14-year } \\
\text { follow-up DHEAS } \\
(\mu \mathrm{g} / \mathrm{ml})(\mu \mathrm{mol} / \mathrm{l})\end{array}$} & \multirow{2}{*}{$\begin{array}{l}\text { Range of } 10-\text { to } \\
14 \text {-year follow- } \\
\text { up DHEAS } \\
(\mu \mathrm{g} / \mathrm{ml})(\mu \mathrm{mol} / \mathrm{l})\end{array}$} & \multirow{2}{*}{$\begin{array}{l}\text { 10- to 14-year } \\
\text { difference in DHEAS } \\
(\mu \mathrm{g} / \mathrm{ml})(\mu \mathrm{mol} / \mathrm{l})\end{array}$} & \multirow{2}{*}{$\begin{array}{l}\text { Annual } \\
\text { percentage } \\
\text { change } \\
\text { DHEAS }\end{array}$} & \multicolumn{3}{|c|}{$\begin{array}{c}\text { Distribution of change } \\
\text { by } \pm 10 \%\end{array}$} & \multicolumn{2}{|c|}{$\begin{array}{l}\text { Distribution of } \\
\text { change by } \\
\text { regression to the } \\
\text { mean criteria }\end{array}$} \\
\hline & & & & & & & & $\begin{array}{c}\text { Decrease } \\
(\%)\end{array}$ & $\begin{array}{c}\text { Same } \\
(\%)\end{array}$ & $\begin{array}{c}\text { Increase } \\
(\%)\end{array}$ & $\begin{array}{c}\text { Decrease } \\
(\%)\end{array}$ & $\begin{array}{c}\text { Increase } \\
(\%)\end{array}$ \\
\hline $60-64$ & 66 & $\begin{array}{c}0.80 \pm 0.56 \\
(2.20 \pm 1.53)\end{array}$ & $\begin{array}{c}0.15-3.00 \\
(0.41-8.14)\end{array}$ & $\begin{array}{c}0.52 \pm 0.34 \\
(1.42 \pm 0.94)\end{array}$ & $\begin{array}{l}0.15-1.73 \\
(0.41-4.70)\end{array}$ & $\begin{array}{c}-0.28 \pm 0.40 \\
(-0.77 \pm 1.09)\end{array}$ & $-2.0 \pm 3.9$ & 71 & 14 & 15 & 82 & 18 \\
\hline $65-69$ & 87 & $\begin{array}{c}0.79 \pm 0.48 \\
(2.14 \pm 1.30)\end{array}$ & $\begin{array}{c}0.15-2.52 \\
(0.41-6.84)\end{array}$ & $\begin{array}{c}0.53 \pm 0.36 \\
(1.46 \pm 0.99)\end{array}$ & $\begin{array}{c}0.15-1.94 \\
(0.41-5.27)\end{array}$ & $\begin{array}{c}-0.25 \pm 0.29 \\
(-0.68 \pm 0.81)\end{array}$ & $-2.1 \pm 4.7$ & 75 & 12 & 13 & 85 & 15 \\
\hline $70-74$ & 46 & $\begin{array}{c}0.60 \pm 0.40 \\
(1.65 \pm 1.10)\end{array}$ & $\begin{array}{c}0.15-1.83 \\
(0.41-4.97)\end{array}$ & $\begin{array}{c}0.41 \pm 0.33 \\
(1.13 \pm 0.92)\end{array}$ & $\begin{array}{c}0.15-1.65 \\
(0.41-4.48)\end{array}$ & $\begin{array}{c}-0.19 \pm 0.31 \\
(-0.52 \pm 0.85)\end{array}$ & $-2.4 \pm 3.1$ & 76 & 13 & 11 & 89 & 11 \\
\hline $75+$ & 8 & $\begin{array}{c}0.43 \pm 0.29 \\
(1.19 \pm 0.80)\end{array}$ & $\begin{array}{c}0.15-0.96 \\
(0.41-2.61)\end{array}$ & $\begin{array}{c}0.32 \pm 0.20 \\
(0.88 \pm 0.57)\end{array}$ & $\begin{array}{l}0.15-7.40 \\
(0.41-2.01)\end{array}$ & $\begin{array}{l}-0.11 \pm 0.28 \\
(-0.32 \pm 0.78)\end{array}$ & $-1.2 \pm 4.3$ & 37.5 & 37.5 & 25 & 88 & 12 \\
\hline All & 207 & $\begin{array}{c}0.74 \pm 0.49 \\
(2.00 \pm 1.33)\end{array}$ & $\begin{array}{c}0.15-3.00 \\
(0.41-8.14)\end{array}$ & $\begin{array}{c}0.50 \pm 0.35 \\
(1.36 \pm 0.95)\end{array}$ & $\begin{array}{c}0.15-1.94 \\
(0.41-5.27)\end{array}$ & $\begin{array}{l}-0.24 \pm 0.34 \\
(-0.65 \pm 0.92)\end{array}$ & $-2.1 \pm 4.1$ & 72 & 14 & 14 & 85 & 15 \\
\hline
\end{tabular}

Mean values are shown \pm S. 
Table 4 Determinants of annualized absolute change in DHEAS.

\begin{tabular}{lrrc}
\hline Variables & $\boldsymbol{\beta}$ coefficient & Model $\boldsymbol{R}^{2}$ & $\boldsymbol{P}$ value \\
\hline Baseline DHEAS $(\mu \mathrm{g} / \mathrm{ml})$ & -0.054 & 0.74 & $<0.0001$ \\
Adjusted for age & -0.054 & 0.74 & $<0.0001$ \\
Adjusted for sex & -0.052 & 0.74 & $<0.0001$ \\
Sex* & 0.038 & 0.19 & $<0.0001$ \\
Adjusted for baseline DHEAS & 0.006 & 0.74 & 0.008 \\
Adjusted for age & 0.039 & 0.21 & $<0.0001$ \\
Age (years) & 0.001 & 0.01 & 0.008 \\
Adjusted for baseline DHEAS & 0.000 & 0.73 & 0.734 \\
Adjusted for sex & 0.002 & 0.21 & 0.004 \\
Weight at baseline $(\mathrm{kg})$ & -0.001 & 0.04 & $<0.0001$ \\
Adjusted for baseline DHEAS & -0.000 & 0.74 & 0.005 \\
Adjusted for age & -0.001 & 0.05 & $<0.0001$ \\
Adjusted for sex & 0.000 & 0.19 & 0.314 \\
Weight change $(\mathrm{kg})$ & -0.001 & 0.00 & 0.162 \\
BMl at baseline $\left(\mathrm{kg} / \mathrm{m}^{2}\right)$ & 0.000 & 0.02 & 0.912 \\
Change in BMI $\left(\mathrm{kg} / \mathrm{m}^{2}\right)$ & -0.001 & 0.00 & 0.371 \\
Smoking & -0.017 & 0.01 & 0.008 \\
Adjusted for baseline DHEAS & -0.001 & 0.74 & 0.684 \\
Adjusted for age & -0.015 & 0.02 & 0.018 \\
Adjusted for sex & -0.017 & 0.20 & 0.002 \\
\hline
\end{tabular}

${ }^{*}$ Male is the reference in all models.

cross-sectional studies $(4,6,40)$, and differ from other longitudinal studies that reported increases in DHEAS in $10-40 \%$ of ageing individuals of both sexes (7-9, 24, 41). Orentreich et al. (7) noted that $13 \%$ of 97 normal, healthy men aged 32-83 years showed no change and $20 \%$ showed increases in plasma DHEAS over a 13-year period. Kahonen et al. (8) reported that DHEAS did not decrease over 5 years in 30\% of 71 men and $40 \%$ of 200 women aged 75 years and older. Mazat and colleagues (9) reported a 7-year increase in plasma DHEAS in approximately one-third of 119 male, and 171 female, community-dwelling elders whose mean age was 74 years.

We considered several possible explanations for the discrepancies in the findings for DHEAS change among longitudinal studies. First, different definitions

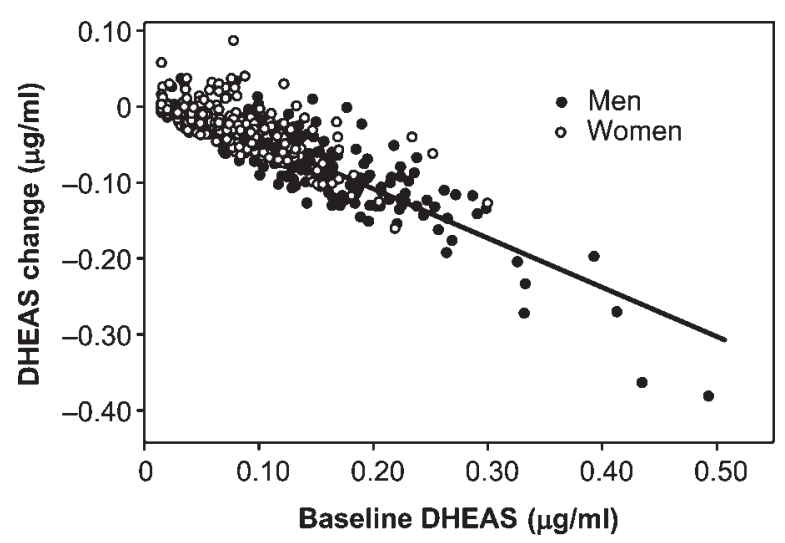

Figure 1 Change in DHEAS levels over a 10- to 14-year period as a function of baseline DHEAS levels among 242 men and 207 postmenopausal women, aged 60-77 years at baseline. Conversion factor: $\mu \mathrm{g} / \mathrm{ml} \times 2.74=\mu \mathrm{mol} / \mathrm{l}$. of change were used to classify whether DHEAS levels decreased, increased or stayed the same over time. Kahonen et al. (8) chose the standard deviation of mean 5-year changes in DHEAS as a criterion for change. By definition, this imposes set boundaries on the number of individuals who could be classified as staying the same without taking into account baseline levels of DHEAS. Mazat et al. (9) used a 19\% definition of change for men and women, based on work by Orentreich et al., who reported a mean 19\% intra-individual variability in circulating DHEAS levels in four men aged 36-59 over 2 years (6). This definition of change may not be appropriate for women or men older than age 60 $(38-39)$.

Secondly, baseline DHEAS levels are clearly the most important predictor of DHEAS change in both sexes, accounting for $74 \%$ of the variability in follow-up DHEAS levels in the present study. Higher initial levels led to more pronounced declines and lower initial levels tended to stay the same or increase. For each $1 \mu \mathrm{g} / \mathrm{ml}$ increment in baseline DHEAS, levels decreased by an additional $0.05 \mu \mathrm{g} / \mathrm{ml}$ per year. The higher proportion of those whose DHEAS levels did not decrease in the Kahonen et al. (8) and Mazat et al. (9) studies may have been due to the older age and lower initial DHEAS levels at baseline in their samples, as well as to the shorter duration of follow-up, compared with the present study.

Thirdly, no previous studies have reported the effect of regression to the mean in explaining changes in DHEAS over time. Regression to the mean is a common statistical phenomenon that should be considered during the analysis of endocrine studies of repeat hormone measures. The main effect of regression to the mean is to bring extreme measures closer to the population mean on retesting when the measures are imperfectly correlated (10-13), as seen in longitudinal studies of DHEAS. Kahonen et al. (8) found correlations of 0.67 between baseline and follow-up DHEAS levels compared with 0.69 in the present study. Moffat and colleagues (24) reported a correlation of 0.80 between baseline and 2-year follow-up DHEAS levels, while Nafziger et al. (41) reported a value of 0.83 after a 5 -year interval. In the present study, $28 \%$ of women had DHEAS levels that remained stable or increased during the study period compared with only $5 \%$ of men. When a regression towards the mean artifact was accounted for, only $15 \%$ of women showed increasing DHEAS levels. If regression to the mean is not considered, results from longitudinal studies of DHEAS change may be misleading, and the contribution of underlying biological mechanisms to DHEAS change overestimated.

The concept of regression to the mean is a particularly important consideration in longitudinal studies of hormone change when the specimens are obtained from a non-random sample of the population. If subjects or specimens are selected because of a biological 
characteristic that is different from the underlying population average, and if regression to the mean is not properly accounted for, the results of the study may be biased (13). For the present study, only 35\% of all baseline participants could be included in the final analysis. According to statistical criteria, survi$\mathrm{val} /$ participant bias should not have affected our results because age-adjusted DHEAS levels at baseline did not differ among those who were included and those who did not participate in the follow-up study, and DHEAS did not predict mortality in this cohort (42). Nonetheless, our results indicated an overestimation of no change or increase in $13 \%$ of the women in this sample when regression to the mean was not accounted for.

The underlying mechanisms of DHEAS change with advancing age are thought to be related to morphological and functional changes in the zona reticularis of the ageing human adrenal cortex. Declines in DHEAS levels have been attributed to atrophy of the adrenal cortical cell mass and a loss of adrenal androgen biosynthesis $(43,44)$. Observed increases in DHEAS are more difficult to explain. One possibility is that the adrenal gland eventually reaches a minimum secretory threshold, and that the greater frequency of observed increases in DHEAS in older women reflects a fluctuating level of this hormone within a narrow lower range, which may have little physiological importance. Reduced sulphatase activity and decreased renal clearance of DHEAS are other possible mechanisms, but there is a paucity of data to support these explanations.

In the present study, sex was an independent predictor of DHEAS change, with women showing a lower rate of decline and a higher propensity for increasing DHEAS levels. Kahonen et al. (8) reported similar sex differences that persisted up to the age of 80 years. A cross-sectional study of the Rancho Bernardo cohort (40) reported that DHEAS levels tended to plateau in women aged 60-80 years, but continued to decline after age 80. Only Mazat et al. (9) observed the opposite, with rates of DHEAS decline that were twice as high in older women $(3.9 \% /$ year $)$ than men $(2.3 \% /$ year). Our findings suggest that there exist unknown fundamental sex differences in the factors regulating adrenal androgen biosynthesis or clearance. Genetic influences may partially explain the sex-specific variations in DHEAS levels over the lifespan (45-48). Another possibility is that DHEAS plays different physiological roles in men and women, and has correspondingly different feedback mechanisms. Jakubowicz et al. (49) showed that weight loss was associated with a $125 \%$ increase in serum DHEAS in obese men, but DHEAS levels did not change with weight loss in women after equivalent reductions in BMI and serum insulin. In the present study, DHEAS levels did not vary with changes in BMI in either sex, but changes in BMI were minimal $\left(-0.3 \pm 2.2 \mathrm{~kg} / \mathrm{m}^{2}\right)$ and few male and female participants were obese (mean baseline BMI 25.6 \pm 2.9 and
$24.8 \pm 3.8 \mathrm{~kg} / \mathrm{m}^{2}$ respectively), with the women in this sample being thinner than the national average (50). The sex-specific relationship of DHEAS to body composition and fat distribution warrants investigation.

It should be noted that plasma DHEAS samples from the initial and follow-up visits were not assayed at the same time, and calculated changes in DHEAS levels were based on one single assay at each visit. However, assays were performed by the same person in the same laboratory using the same assay for both visits. Further, single measurements of DHEAS have been shown to characterize average levels reliably in older individuals over a 1- to 3-year period $(39,51)$. Changes in hormone levels during long-term storage are also unlikely to explain the observed associations. Hormone levels were measured in never previously thawed plasma and levels did not vary by season of sampling or duration of storage. In addition, others have shown that levels of steroid hormones are relatively stable in frozen plasma stored for 3-10 years $(7,52,53)$. There was little risk of contamination by over-the-counter DHEA supplement use in this study, because dietary DHEA supplements were not introduced to the public market until the 1990s, years after collection of all plasma samples for the present study.

In summary, this 10-to 14-year longitudinal study of changes in DHEAS levels shows that DHEAS levels continue to decline into late adulthood in nearly all men and in the majority of women. Levels appear to plateau or increase among individuals who have the lowest DHEAS levels, but some of this phenomenon is explained by regression to the mean. Baseline DHEAS appears to be the most important predictor of DHEAS change, with sex being the only other independent predictor. Smoking status, age and baseline weight possibly exert small additional effects on DHEAS change through their effects on baseline DHEAS. Further research is needed to clarify the underlying mechanisms and physiological importance of the significant decrease in circulating DHEAS levels in the majority of older adults, and these investigations need to consider various definitions of change and regression to the mean.

\section{References}

1 Labrie F. Intracrinology. Molecular Cell Endocrinology 199178 C113-C118.

2 Labrie F, Belanger A, Luu-The V, Labrie C, Simard J, Cusan L, Gomez JL \& Candas B. DHEA and the intracrine formation of androgens and estrogens in peripheral target tissues: its role during aging. Steroids $199863322-328$.

3 Hornsby PJ. Biosynthesis of DHEAS by the human adrenal cortex and its age-related decline. Annals of the New York Academy of Science $199577429-46$.

4 Laurie F, Belanger A, Cuban L \& Candas B. Marked decline in serum concentrations of adrenal C19 sex steroid precursors and conjugated androgen metabolites during aging. Journal of Clinical Endocrinology and Metabolism 199782 2392-2402. 
5 Laughlin GA, Barrett-Connor E, Kritz-Silverstein D \& von Muhlen D. Hysterectomy, oophorectomy, and endogenous sex hormone levels in older women: the Rancho Bernardo Study. Journal of Clinical Endocrinology and Metabolism $2000 \mathbf{8 5}$ 645-651.

6 Orentreich N, Brind JL, Rizer RL \& Vogelman JH. Age changes and sex differences in serum dehydroepiandrosterone sulphate concentrations throughout adulthood. Journal of Clinical Endocrinology and Metabolism $198459551-555$.

7 Orentreich N, Brind JL, Vogelman JH, Andres R \& Baldwin H. Long-term longitudinal measurements of plasma dehydroepiandrosterone sulfate in normal men. Journal of Clinical Endocrinology and Metabolism $1992751002-1004$.

8 Kahonen MH, Tilvis RS, Jokkonen J, Pitkala K \& Harkonen M. Predictors and clinical significance of declining plasma dehydroepiandrosterone sulfate in old age. Journal of Aging, Clinical and Experimental Research $200012308-314$.

9 Mazat L, Lafont S, Berr C, Debuire B, Tessier JF, Dartigues JF \& Baulieu EE. Prospective measurements of dehydroepiandrosterone sulfate in a cohort of elderly subjects: relationship to gender, subjective health, smoking habits and 10-year mortality. PNAS 2001 98 8145-8150.

10 Campbell DT \& Kenny DA. A Primer on Regression Artifacts. New York: Guilford Press, 1999.

11 Streiner DL. Regression toward the mean: its etiology, diagnosis and treatment. Canadian Journal of Psychiatry $2001 \mathbf{4 6} 72-76$

12 Trochim W. The Research Methods Knowledge Base, 2nd edn. Cincinnati, Ohio: Atomic Dog Publishing, 2000.

13 Davis CE. The effect of regression to the mean in epidemiologic and clinical studies. Journal of Epidemiology $1976 \mathbf{1 0 4} 493-498$.

14 Shepard DS \& Finison LJ. Blood pressure reductions: correcting for regression to the mean. Preventive Medicine 198312 304-317.

15 Tilvis RS, Kahonen M \& Harkonen M. Dehydroepiandrosterone sulphate, diseases and mortality in a general aged population. Aging (Milano) 199911 30-34.

16 Barrett-Connor E \& Goodman-Gruen D. The epidemiology of DHEAS and cardiovascular disease. Annals of the New York Academy of Science $1995 \mathbf{7 7 4}$ 259-270.

17 Newcomer LM, Manson JE, Barbieri RL, Hennekins CH \& Stampfer MJ. Dehydroepiandrosterone sulphate and the risk of myocardial infarction in US male physicians: a prospective study. American Journal of Epidemiology 1994140 870-875.

18 Feldman HA, Johannes C, McKinlay JB \& Longcope C. Low dehydroepiandrosterone sulfate and heart disease in middle-aged men: cross-sectional results from the Massachusetts Male Aging Study. American Journal of Epidemiology $1998 \mathbf{8} 217-228$.

19 Johannes CB, Stellato RK, Feldman HA, Longcope C \& McKinlay JB. Relation of dehydroepiandrosterone and dehydroepiandrosterone sulfate with cardiovascular disease risk factors in women: longitudinal results from the Massachusetts Women's Health Study. Journal of Clinical Epidemiology 199952 95-103.

20 Trivedi DP \& Khaw KT. Dehydroepiandrosterone sulphate and mortality in elderly men and women. Journal of Clinical Endocrinology and Metabolism $2001 \mathbf{8 6} 4171$-4177.

21 Herrington DM. Dehydroepiandrosterone and coronary atherosclerosis. Annals of the New York Academy of Science 1995774 $271-280$.

22 Legrain S, Berr C, Frenoy N, Gourlet V, Debuire B \& Baulieu E. Dehydroepiandrosterone sulphate in a long-term care aged population. Gerontology $1995 \mathbf{4 1} 343-351$.

23 Berr C, Lafont S, Debuire B, Dartigues JF \& Baulieu EE. Relationships of dehydroepiandrosterone-sulfate in the elderly with functional, psychological, and mental status, and short-term mortality; a French community-based study. PNAS 199693 $13410-13415$.

24 Moffat SD, Zonderman AB, Harman SM, Blackman MR, Kawas C \& Resnick SM. The relationship between longitudinal declines in dehydroepiandrosterone sulfate concentrations and cognitive performance in older men. Archives of Internal Medicine 2000 $1602193-2198$.
25 Cuckle H, Stone R, Smith D, Wald N, Brammer M, Hajimohammedreza I, Levy R, Chard T \& Perry L. Dehydroepiandrosterone sulphate in Alzheimer's disease. Lancet 1990336 449-450.

26 Barrett-Connor E \& Edelstein SL. A prospective study of dehydroepiandrosterone sulfate and cognitive function in an older population: the Rancho Bernardo Study. Journal of the American Geriatrics Society 199442 420-423.

27 Yaffe K, Ettinger B, Pressman A, Seeley D, Whooley M, Schaefer C \& Cummings S. Neuropsychiatric function and dehydroepiandrosterone sulfate in elderly women: a prospective study. Biological Psychiatry 199843 694-700.

28 Vallee M, Mayo W \& Le Moal M. Role of pregnenolone, dehydroepiandrosterone and their sulfate esters on learning and memory in cognitive aging. Brain Research Reviews 200137 $301-312$.

29 Ravaglia R, Forti P, Maioli F, Sacchetti L, Nativio V, Scali CR, Mariani E, Zanardi V, Stefanini S \& Macini PL. Dehydroepiandrosterone-sulfate serum levels and common age-related diseases: results from a cross-sectional Italian study of a general elderly population. Experimental Gerontology 200237 701-712.

30 Greendale GA, Edelstein S \& Barrett-Connor E. Endogenous sex steroids and bone mineral density in older women and men: The Rancho Bernardo Study. Journal of Bone and Mineral Research $1997121833-1843$.

31 Clarke BL, Ebeling PR, Jones JD, Wahner HW, O'Fallon WM, Riggs BL \& Fitzpatrick LA. Predictors of bone mineral density in aging healthy men varies by skeletal site. Calcified Tissue International 200270 137-145.

32 Barrett-Connor E, Kritz-Silverstein D \& Edelstein SL. A prospective study of dehydroepiandrosterone sulfate (DHEAS) and bone mineral density in older men and women. American Journal of Epidemiology $1993137201-206$.

33 Barrett-Connor E, von Muhlen D, Laughlin GA \& Kripke A. Endogenous levels of dehydroepiandrosterone sulphate, but not other sex hormones, are associated with depressed mood in older women: The Rancho Bernardo Study. Journal of the American Geriatrics Society $1999 \mathbf{4 7} 685-691$.

34 Ebeling P \& Koivisto VA. Physiological importance of dehydroepiandrosterone. Lancet $19943431479-1481$.

35 The Endogenous Hormones and Breast Cancer Collaborative Group. Endogenous sex hormones and breast cancer in postmenopausal women: reanalysis of nine prospective studies. Journal of the National Cancer Institute 200294 606-616.

36 Le Bail JC, Lotfi H, Charles L, Pepin D \& Habrioux G. Conversion of dehydroepiandrosterone sulfate at physiological plasma concentration into estrogens in MCF-7 cells. Steroids $2002 \mathbf{6 7}$ 1057-1064.

37 Helzlsouer KJ, Gordon GB, Alberg A, Bush TL \& Comstock GW. Relationship of prediagnostic serum levels of dehydroepiandrosterone and dehydroepiandrosterone sulfate to the risk of developing premenopausal breast cancer. Cancer Research 199252 1-4.

38 Thomas G, Frenoy N, Legrain S, Sebag-Lanoe R, Baulieu EE \& Debuire B. Serum dehydroepiandrosterone sulphate levels as an individual marker. Journal of Clinical Endocrinology and Metabolism $1994791273-1276$.

39 Muti P, Trevisan M, Micheli A, Krogh V, Bolelli G, Sciajno R \& Berrino F. Reliability of serum hormones in premenopausal and postmenopausal women over a one-year period. Cancer Epidemiology Biomarkers and Prevention 19965 917-922.

40 Laughlin GA \& Barrett-Connor E. Sexual dimorphism in the influence of advanced aging on adrenal hormone levels: the Rancho Bernardo Study. Journal of Clinical Endocrinology and Metabolism $2000853561-3568$.

41 Nafziger AN, Bowlin SJ, Jenkins PL \& Pearson TA. Longitudinal changes in dehydroepiandrosterone concentrations in men and women. Journal of Laboratory and Clinical Medicine 1998131 316-323.

42 Barrett-Connor E \& Goodman-Gruen D. Dehydroepiandrosterone sulfate does not predict cardiovascular death in postmenopausal 
women: the Rancho Bernardo Study. Circulation 199591 1757-1760.

43 Parker CR, Mixon RL, Brissie RM \& Grizzle WE. Aging alters zonation in the adrenal cortex of men. Journal of Clinical Endocrinology and Metabolism $1997 \mathbf{8 2}$ 3898-3901.

44 Hornsby PJ. Aging of the human adrenal cortex. Ageing Research Reviews $20021229-242$.

45 Rotter JI, Wong L, Lifrak ET \& Parker LN. A genetic component to the variation of dehydroepiandrosterone sulfate. Metabolism 1985 $34731-736$

46 An P, Rosmond R, Borecki IB, Ukkola O, Rice T, Gagnon J, Rankinen T, Leon AS, Skinner JS, Wilmore JH, Bouchard C \& Rao DC. Genome-wide linkage scan to detect loci influencing levels of dehydroepiandrosterones in the HERITAGE Family Study. Metabolism 200150 1315-1322.

47 Legro RS, Kunselman AR, Demers L, Wang SC, Bentley-Lewis R \& Dunaif A. Elevated dehydroepiandrosterone sulfate levels as the reproductive phenotype in the brothers of women with polycystic ovary syndrome. Journal of Clinical Endocrinology and Metabolism $2002872134-2138$.

48 Rice T, Sprecher DL, Borecki IB, Mitchell LE, Laskarzewski PM \& Rao DC. The Cincinnati Myocardial Infarction and Hormone Family Study: family resemblance for dehydroepiandrosterone sulfate in control and myocardial infarction families. Metabolism $1993421284-1290$.
49 Jakubowicz DJ, Beer NA, Beer RM \& Nestler JE. Disparate effects of weight reduction by diet on serum dehydroepiandrosteronesulfate levels in obese men and women. Journal of Clinical Endocrinology and Metabolism 199580 3373-3376.

50 Barrett-Connor E. The prevalence of diabetes mellitus in an adult community as determined by history of fasting hyperglycemia. American Journal of Epidemiology 1980111 705-712.

51 Hankinson SE, Manson JE, Spiegelman D, Willett WC, Longcope C \& Speizer FE. Reproducibility of plasma hormone levels in postmenopausal women over a 2-3 year period. Cancer Epidemiology Biomarkers and Prevention $1995 \mathbf{4} 649-654$.

52 Kley HK, Schlaghecke R \& Kruskemper HL. Stability of steroids in plasma over a 10 year period. Journal of Clinical Chemistry and Clinical Biochemistry 198523 875-878.

53 Bolelli G, Muti P, Micheli A, Sciajno R, Franceschetti F, Krogh V, Pisani P \& Berrino F. Validity for epidemiological studies of long-term cryoconservation of steroid and protein hormones in serum and plasma. Cancer Epidemiology Biomarkers and Prevention $19954509-513$.

Received 15 June 2004

Accepted 13 September 2004 